\title{
Dynamics of Kaolinite-Urea Nanocomposites via Coupled DMSO-Hydroxyaluminum Oligomeric Intermediates
}

\author{
Siafu Ibahati Sempeho, ${ }^{1}$ Hee Taik Kim, ${ }^{2}$ Egid Mubofu, ${ }^{3}$ Alexander Pogrebnoi, \\ Godlisten Shao, ${ }^{2,4}$ and Askwar Hilonga ${ }^{1}$ \\ ${ }^{1}$ Department of Materials Science and Engineering, The Nelson Mandela African Institution of Science and Technology, \\ P.O. Box 447, Arusha, Tanzania \\ ${ }^{2}$ Department of Chemical Engineering, Hanyang University, 1271 Sa 3-dong, Sangnok-gu, Ansan-si, \\ Gyeonggi-do 426-791, Republic of Korea \\ ${ }^{3}$ Chemistry Department, University of Dar es Salaam, P.O. Box 35091, Dar es Salaam, Tanzania \\ ${ }^{4}$ Chemistry Department, Mkwawa University College of Education, P.O. Box 35091, Dar es Salaam, Tanzania
}

Correspondence should be addressed to Hee Taik Kim; khtaik@hanyang.ac.kr and Askwar Hilonga; askwar.hilonga@nm-aist.ac.tz

Received 9 May 2015; Accepted 19 August 2015

Academic Editor: Marino Lavorgna

Copyright (C) 2015 Siafu Ibahati Sempeho et al. This is an open access article distributed under the Creative Commons Attribution License, which permits unrestricted use, distribution, and reproduction in any medium, provided the original work is properly cited.

Kaolinite-urea nanocomposites were prepared via intercalation reactions in an attempt to investigate the dynamic nature of kaolinite morphology for advanced applications in controlled release systems (CRS). Characterization was done using SEM-EDX, XRF, ATR-FTIR, XRD, and DT/DTG; Andreasen pipette sedimentation technique was used to determine the grain size distribution of the raw kaolinite. The X-ray diffraction pattern revealed the existence of an FCC Bravais lattice where the intercalation ratios attained were $51.2 \%, 32.4 \%, 7.0 \%$, and $38.4 \%$ for hydroxyaluminum oligomeric intercalated kaolinite, substituted urea intercalated kaolinite, calcined DMSO intercalated kaolinite, and hydroxyaluminum reintercalated kaolinite, respectively, along with their respective crystallite sizes of $33.51-31.73 \mathrm{~nm}, 41.92-39.69 \mathrm{~nm}, 22.31-21.13 \mathrm{~nm}$, and $41.86-39.63 \mathrm{~nm}$. The outcomes demonstrated that the employed intercalation routes require improvements as the intercalation reactions were in average only $\approx 32.3 \%$. The observations unveiled that it is possible to manipulate kaolinite structure into various morphologies including dense-tightly packed overlapping euhedral pseudo hexagonal platelets, stacked vermiform morphologies, postulated forms, and unique patterns exhibiting self-assembled curled glomeruli-like morphologies. Such a diversity of kaolinite morphologies expedites its advanced applications in the controlled release systems (CRS) such as drug delivery systems and controlled release fertilizers (CRFs).

\section{Introduction}

Contemporaneously, researchers have been interested in the investigation of the intercalation reactions (IRs) that involves kaolinite layered phyllosilicates for the purpose of scientific and technological advancements in the areas of catalysis; water filtration; composites; nanotechnology; controlled released formulations [1, 2] such as drug delivery systems (DDSs) and controlled release fertilizers (CRFs) [3-10]. Progressive application of kaolinite in the engineering designs has been practically feasible owing to the fact that kaolinite (which is an inexpensive chemical mineral) can be modified through ion exchange mechanisms by just intercalation of ionic species into the kaolinite interlayer spaces. Primarily, the hydrated form of the kaolinite mineral consists of kaolinite sheets interspersed with monomolecular sheets of water molecules. This is an essential feature for intercalation reactions; elsewhere this property was termed as clay' advantageous properties [11, 12]. According to [13], the fate of the mentioned ion-exchange mechanism includes (i) the widening of gap between the single sheets thereby facilitating the insertion of organic species into the interlayer spaces and 
(ii) the alteration of the surface charges of each single sheets from being hydrophilic to organophilic [14]. The likelihood that an intercalation reaction will be feasible depends on the interactions between polar functional group-containing compounds and layered phyllosilicates such as kaolinite; in most cases the mechanism involves the interaction between clays with exchangeable cations plus interactions with siloxane surfaces via surface adsorption [15]. In addition, the ion-dipole mechanism is also known to influence kaolinite interactions [15]; this mechanism involves either the direct interactions of organic compounds with exchangeable cations or in-direct interaction through the intermediation of water molecules surrounding the cations. By the same token, an increase in the charge valence of exchangeable cation is known to enhance the ion-dipole interactions [15-18]. However, it has been evidenced that nonpolar surface interactions between organic compounds and the siloxane surfaces of the clays may also occur. Likewise, the weakening of ion-dipole interactions may take place at times when water molecules surrounding strongly hydrated cations such as $\mathrm{Ca}^{2+}$ and $\mathrm{Mg}^{2+}$ inhibit the direct interaction between polar functional groups and the exchangeable cations [15, 19-21].

Profoundly, the presence of charges on the clay minerals is an inherent property which facilitate most intercalation reactions and the main source of these charges on the clay minerals is isomorphous substitution reactions (permanent charge due to isomorphous substitution) for the reason that it confers permanent charge on their surface of the layers [1].

Furthermore, the development of charges on the clay surfaces can also be attributed to (i) the ionization of hydroxyl groups and (ii) the presence of surface and broken-edge $\mathrm{OH}^{-}$groups apart from the major isomorphous substitution reactions [1]. That is to say, $\mathrm{pH}$-dependent charge (which is not permanent as for the isomorphous substitution) develops when there is ionization of hydroxyl groups on the surfaces of other particles ( $\mathrm{pH}$-dependent charges on the edges describing the fact that, at lower $\mathrm{pH}, \mathrm{H}^{+}$are tightly bound and so have less tendency to intercalations). Besides, the presence of surface and broken-edge $\mathrm{OH}^{-}$groups (which exposes the functional groups for maximum interactions) gives rise to the ideal electronegativity (which is a necessary property in this context) along with the kaolinite particles' ability to adsorb and so intercalate ionic species. Thus, as pointed out by [1], clay particles are stacked in layers like sheets of papers where each sheet is slightly separated from those on either side and has negative charges on it which could be balanced by positive ionic species, phenomena which are critical for the kaolinite interactions including intercalations reactions among others.

In this paper, we report the dynamic morphological changes in the kaolinite nanocomposite structures based on the urea intercalated kaolinite as a function of DMSOhydroxyaluminum oligomeric intermediate intercalation compounds and calcination reactions. The aim was to study the changes associated with coupling DMSO intercalated kaolinite along with hydroxyaluminum oligomeric cations to prepare well-ordered self-assembled nanocomposite excipients (for use in the CRFs and DDs) exhibiting unique curled patterns.

\section{Materials, Preparation, and Characterization}

2.1. Materials. Kaolinite was collected at Pugu hills in the Coast region Kisarawe Tanzania by using quartering sampling technique described in [22]. Urea (ACS reagent, 99$100 \%$ ) was supplied by Sigma Aldrich, DMSO (Extra pure, $\geq 99.5 \%$ ) was supplied by Daejung Chemicals \& Metals Co. Ltd., Gyonggi-do, Korea, sodium chloride (Extra pure, $\geq 99.0 \%$ ) was supplied by Samchun Pure Chemicals Co., Ltd., Gyonggi-do, Korea, silver chloride (ACS reagent, 99.0\%) was supplied by Sigma Aldrich, deionized distilled water (D.I.) was supplied by Professor Kim's Lab, sodium hydroxide (extra pure grade, min 93.0\%) was supplied by Duksan Pure Chemical, Ansan City, Kyungkido, South Korea, and aluminium chloride (99.99\%) was supplied by Junsei Chemical Co., Ltd., Japan.

\subsection{Materials Preparation}

2.2.1. Beneficiation and Treatment of Raw Samples. Wet beneficiation technique was achieved by simple size separation using "classifier." The method involved the separation of fine platy kaolinite from coarser quartz, feldspar mica, and other impurities using different setting velocities associated with particle size as governed by Stockes's law [43-50]. The entire procedure which involved crushing to pulverization and soaking as well as running the classifier unit to drying has been comprehensively described in [51]. Pugu kaolinite $(10 \mathrm{~g})$ was dispersed in $1000 \mathrm{~cm}^{3}$ of $0.1 \mathrm{M} \mathrm{NaCl}$ solution and treated ultrasonically at $50^{\circ} \mathrm{C}$ for 30 hours and then constantly magnetically stirred for more 30 hours. The product was filtered under vacuum filter and washed several times to remove excessive chlorides; washing was stopped after negative reaction with $\mathrm{AgNO}_{3}$. The washed product was dried in a vacuum oven at $60^{\circ} \mathrm{C}$ and stockpiled as $\mathrm{B}_{1}$.

2.2.2. Preparation of Kaolinite-Intercalation Nanomaterials. $\mathrm{AlCl}_{3}$ solution $(0.1 \mathrm{M})$ was mixed with $0.1 \mathrm{M} \mathrm{NaOH}$ solution at a 1:2 molar mixing ratio, respectively. The mixture was stirred at $85^{\circ} \mathrm{C}$ for 6 hours and then aged for 12 hours. A $5 \%$ beneficiated kaolinite suspension was prepared and was ultrasonically mixed with an excess of hydroxyaluminum oligomeric solution at $70^{\circ} \mathrm{C}$ for 3 hours. The product was named $B_{2}$ which was then washed in a vacuum pump to remove unreacted materials and chloride ions as tested by $\mathrm{AgNO}_{3}$ solution. By using $\mathrm{B}_{2}$ powder as a starting material, a small portion was taken and then mixed with $5 \mathrm{~g}$ of urea and stirred for 72 hours at $60^{\circ} \mathrm{C}$. The urea-kaolinite nanocomposite obtained was washed in a vacuum pump with excess water and dried at $60^{\circ} \mathrm{C}$ in a vacuum oven and stored as $B_{3}$. A small portion of beneficiated and modified Pugu kaolinite was magnetically stirred with DMSO solution in a ratio of $1: 6$ for 21 days at $80^{\circ} \mathrm{C}$ with a very small addition of water droplets. The suspension was then aged for 7 days and then washed with excess isopropanol and dried at $60^{\circ} \mathrm{C}$ in a vacuum oven to obtain powder. The DMSO intercalated kaolinite obtained in powder form was calcined at $850^{\circ} \mathrm{C}\left(10^{\circ} \mathrm{C} / \mathrm{min}\right)$ for 8 hours with 6-hour holding time and cooling rate of $7^{\circ} \mathrm{C} / \mathrm{min}$. 
TABLE 1: Chemical composition of the raw materials.

\begin{tabular}{lccccccccccccccc}
\hline \multirow{2}{*}{ Sample } & \multicolumn{1}{c}{ Oxide composition } & \multicolumn{1}{c}{$\mathrm{K}^{2} \mathrm{O}$} & $\mathrm{CaO}$ & $\mathrm{TiO}_{2}$ & $\mathrm{Cr}_{2} \mathrm{O}_{3}$ & $\mathrm{MnO}_{2}$ & $\mathrm{Fe}_{2} \mathrm{O}_{3}$ & $\mathrm{LOI}$ \\
\hline Pugu kaolinite & 63.64 & 31.43 & 0.43 & 0.16 & 0.25 & 0.76 & 1.39 & 0.06 & 0.80 & 0.03 & 0.01 & 1.01 & 0.03 \\
Beneficiated kaolinite & 54.99 & 40.20 & 0.09 & 0.13 & 0.08 & 0.04 & 0.96 & 0.04 & 1.02 & 0.04 & 0.01 & 2.00 & 0.40 \\
\hline
\end{tabular}

The calcined sample was named $\mathrm{B}_{4}$. To the calcined powdered sample, $0.38 \mathrm{~g}$ was measured in a Sartorius analytical balance and mixed with $0.98 \mathrm{~g}$ of urea in excess of hydroxyaluminum oligomeric solution prepared as described above. The mixture was stirred at $105^{\circ} \mathrm{C}$ to dryness and the powder obtained was named $\mathrm{B}_{5}$.

\subsection{Characterization}

2.3.1. Infrared Spectroscopy. By using a Bruker Optic GmbH (alpha model, Laser class 1) Spectrometer with attenuated total reflectance (ATR) the FTIR-ATR measurements were performed in the near infrared region at wavelength between 7500 and $360 \mathrm{~cm}^{-1}$.

2.3.2. X-Ray Diffraction. SIEMENS D-5005 X-ray Diffractometer $(\mathrm{Cu} \mathrm{K} \alpha 1$ radiation and $2 \theta$ scan range which was between $2^{\circ}$ and $65^{\circ}$ ) was used to determine raw kaolinite mineralogy whereas the XRD patterns for the intercalation compounds were executed on RIGAKU COORPERATION, D/MAX-2500/PC X-ray Diffractometer (Cu K $\alpha 1)$ equipped with a back monochromator operating at $40 \mathrm{kV}$ and $100 \mathrm{~mA}$ at the scanning range of $5^{\circ}-80^{\circ}$ with a step of $0.1^{\circ}$ and a time/ step of $1 \mathrm{~s}$.

2.3.3. Thermogravimetry (TG/DTG). Thermograms were taken using TG/STA Linseis STA PT 1000 simultaneous TG/ DTG thermal analyzer at a scanning rate of $5^{\circ} \mathrm{C}$ per min from room temperature to $800^{\circ} \mathrm{C}$ under nitrogen atmosphere.

\subsubsection{Scanning Electron Microscopy-Energy-Dispersive X-Ray} Spectroscopy (SEM-EDAX). The samples surfaces morphology was investigated by using Field Emission Scanning Electron Microscopy (SEM-Hitachi-s-4800, Japan) coupled with EDX device. The accelerated voltage was $15 \mathrm{kV}$.

2.3.5. XRF Analysis. The raw kaolinite was analyzed for chemical composition using X-ray Fluorescence (XRF) employing the Semi Quantitative XRF Analysis technique (SIEMENS SRS $3000 \mathrm{X}$-ray Fluorescence (Rhodium anode, 8 analyzer crystals) with beryllium windows $125 \mu \mathrm{m}$ ).

2.3.6. Indexing the Diffraction Patterns and Particle Size Determination. The X-ray diffraction patterns were indexed by using mathematical method by first determining the unit cell parameter from the peak position and then Miller indices. For the nanocomposites, the crystallite sizes were estimated using X-ray diffraction patterns and the Scherrer's equation whereas the analysis of particle size distribution of the raw kaolinite was done with subsieve analysis technique by applying Andreasen pipette sedimentation method [22, 52].

\section{Results and Discussion}

3.1. Raw Kaolinite Analysis. Oriented as well as randomly oriented whole rock X-ray diffraction as a function of airdrying, glycolation, and heating at $550^{\circ} \mathrm{C}$ revealed the presence of quartz $\left(\mathrm{SiO}_{2}\right)$, clinochlore $\left[\mathrm{Mg}_{5} \mathrm{Al}(\mathrm{Si}, \mathrm{Al})_{4} \mathrm{O}_{10}(\mathrm{OH})_{8}\right]$, and microcline $\left[\mathrm{KAlSi}_{3} \mathrm{O}_{8}\right.$ ] as nonkaolinite portions in the raw kaolinite after beneficiation quartz and microcline disappeared. After beneficiation, kaolinite $\left[\mathrm{Al}_{2} \mathrm{Si}_{2} \mathrm{O}_{5}(\mathrm{OH})_{4}\right]$ was observed to be a dominant phase along with illite $\left[\mathrm{KAl}_{2}\left(\mathrm{Si}_{3} \mathrm{AlO}_{10}\right)(\mathrm{OH})_{2}\right]$ as minor phase. The chemical composition of raw and beneficiated kaolinite used revealed a reduction of silica content from 63.64 to $54.99 \%$ and an increase in alumina content from 31.43 to $40.2 \%$ (Table 1).

3.2. X-Ray Indexing and Particle Size Analysis. Miller indices sequence (Table 2) obtained using the X-ray diffraction pattern (Figure 1) indicated that the kaolinite used had an FCC crystal Bravais lattice structure with the average lattice parameter of $12.597 \AA$. The X-ray diffraction (Figure 1) revealed that the intercalation of oligomeric cations into the kaolinite interlayer spaces $\left(\mathrm{B}_{2}\right)$ proceeded at an apparent intercalation ratio of $51.2 \%$ (Table 3 ) corresponding to the expansion of basal lattice space of about $0.098 \AA$. For the $B_{3}$ nanocomposite the intercalation compound was formed at an intercalation ratio of $32.4 \%$ related to the basal expansion of lattice parameter of about $0.186 \AA$. The intermediate DMSO intercalated kaolinite was found to have an intercalation ratio of $89.2 \%$ prior to calcination; this intercalation ratio dropped to $7.0 \%$ after calcination (for the calcined $\mathrm{B}_{4}$ in Figure 1) and this was attributed to the disintegration of an intercalant DMSO present in the kaolinite interlayer spaces to form corresponding DMSO decomposition material. This drastic drop from $89.2 \%$ to $7.0 \%$ of intercalation ratio is associated with the contraction (instead of the usual expansion of interlayer distances) of about $3.778 \AA$. Following reintercalation of $\mathrm{B}_{4}$ with hydroxyaluminum oligomeric cations the intercalation ratio was raised to $38.4 \%$ (for $\mathrm{B}_{5}$ ) from $7.0 \%$ of $\mathrm{B}_{4}$; this corresponds to the expansion of $0.634 \AA$ in the basal lattice spaces from the compact calcined $\mathrm{B}_{4}$. The particle size of each sample is given in Table 2; the order of particle sizes was observed to be in the following trend: $\mathrm{B}_{3} \approx \mathrm{B}_{5}>\mathrm{B}_{2}>\mathrm{B}_{4}$. Calcination caused a drastic size reduction as seen in Table 2 .

3.3. FT-IR Analysis. The discussion regarding the IR absorption bands on the intercalated kaolinite minerals is mainly limited to the $\mathrm{OH}$ and $\mathrm{Si}-\mathrm{O}$ near infrared absorptions (Figure 2). The presence of characteristic stretching vibrations indicated that the intercalation interactions between the kaolinite interlayer spaces with the intercalating species as 
TABLE 2: Indexed X-ray diffraction patterns.

\begin{tabular}{lccccccc}
\hline Peak & $2 \theta$ & $\sin ^{2} \theta$ & $3 \sin ^{2} \theta / \sin ^{2} \theta_{\min }$ & $h^{2}+k^{2}+l^{2}$ & $h k l$ & $a(\AA)$ & $1(\mathrm{~nm})$ \\
\hline 1 & 12.402 & 0.011668 & 3.158 & 3 & 13 & 320 & 12.352 \\
2 & 24.911 & 0.046518 & 12.592 & 3 & 111 & 12.877 \\
3 & 12.233 & 0.011353 & 3.073 & 12.522 & 0.713 \\
4 & 24.746 & 0.045914 & 12.428 & 3 & 222 & 12.453 \\
5 & 12.086 & 0.011083 & 3.000 & 12 & 111 & 12.673 \\
6 & 24.592 & 0.045353 & 12.276 & 14 & 222 & 12.529 \\
7 & 26.562 & 0.052775 & 14.285 & 8 & 321 & 12.546 \\
8 & 19.581 & 0.028916 & 7.820 & 10 & 220 & 0.723 \\
9 & 22.279 & 0.037326 & 10.104 & 310 & 0.732 \\
\hline
\end{tabular}

TABLE 3: Scherrer's particle size and intercalation ratio.

\begin{tabular}{lcc}
\hline Material & A.I.R. (\%) & Average $l(\mathrm{~nm})$ \\
\hline $\mathrm{B}_{2}$ & 51.2 & $33.51-31.73$ \\
$\mathrm{~B}_{3}$ & 32.4 & $41.92-39.69$ \\
$\mathrm{~B}_{4}$ & 7.0 & $22.31-21.13$ \\
$\mathrm{~B}_{5}$ & 38.4 & $41.86-39.63$ \\
\hline
\end{tabular}

A.I.R.: apparent intercalation ratio. $l$ : particle size.

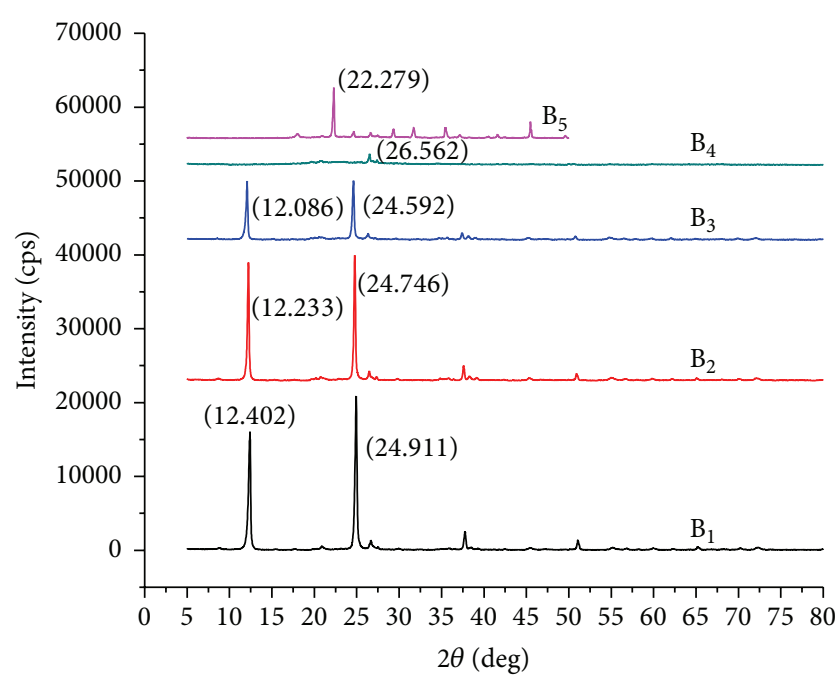

Figure 1: X-ray diffractograms for $\mathrm{B}_{1}, \mathrm{~B}_{2}, \mathrm{~B}_{3}, \mathrm{~B}_{4}$, and $\mathrm{B}_{5}$.

well as with urea fertilizer took place. These vibrations have been summarized in Table 4 .

Essentially, the intercalating species (DMSO) is known to be highly stable at temperatures below $150^{\circ} \mathrm{C}$ above which gradual decomposition starts to form relatively volatile materials in the form of paraformaldehyde including among others dimethyl sulfide, dimethyl disulfide, bis(methylthio)methane, water vapor, and traces of methyl mercaptan and dimethyl sulfone $\left(\mathrm{R}_{1}\right)-\left(\mathrm{R}_{4}\right)$ attributable to the reactions which took place during calcination process to form $\mathrm{B}_{4}$ which corresponds to the absorption bands observed at $1365,1438,1738$, and $2970 \mathrm{~cm}^{-1}$, for $\mathrm{S}=\mathrm{O}$ sulfonyl stretching, $\mathrm{S}=\mathrm{O}$ sulfate ester stretching, $\mathrm{C}=\mathrm{O}$ stretch, and either $\mathrm{CH}$

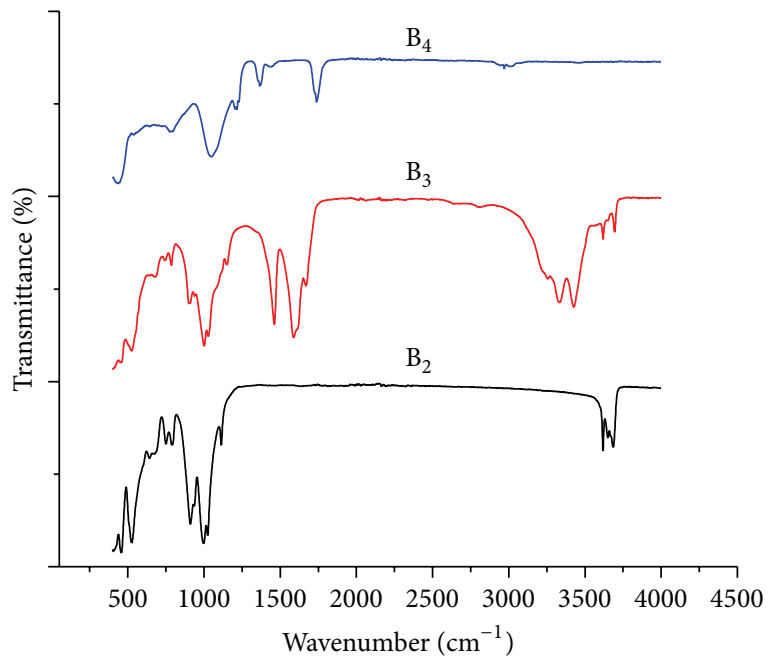

FIgURE 2: ATR-FTIR diffractograms for $\mathrm{B}_{2}, \mathrm{~B}_{3}$, and $\mathrm{B}_{4}$.

stretch or dimeric $\mathrm{OH}$ carboxylic acid stretch, respectively, as seen in the reactions $\left(\mathrm{R}_{1}\right)$ to $\left(\mathrm{R}_{4}\right)[32,33]$ :

$$
\begin{array}{ll}
\mathrm{H}_{3} \mathrm{CSOCH}_{3} \longrightarrow \mathrm{H}_{3} \mathrm{CSH}+\mathrm{HCHO} \Longrightarrow(\mathrm{HCHO})_{x} & \left(\mathrm{R}_{1}\right) \\
2 \mathrm{H}_{3} \mathrm{CSH}+\mathrm{HCHO} \longrightarrow\left(\mathrm{H}_{3} \mathrm{CS}\right)_{2} \mathrm{CH}_{2}+\mathrm{H}_{2} \mathrm{O} & \left(\mathrm{R}_{2}\right) \\
2 \mathrm{H}_{3} \mathrm{CSH}+\mathrm{CH}_{3} \mathrm{SOCH}_{3} & \\
\quad \longrightarrow \mathrm{H}_{3} \mathrm{CSSCH}_{3}+\mathrm{H}_{3} \mathrm{CSCH}_{3}+\mathrm{H}_{2} \mathrm{O} & \left(\mathrm{R}_{3}\right) \\
2 \mathrm{H}_{3} \mathrm{CSOCH}_{3} \longrightarrow \mathrm{H}_{3} \mathrm{CSO}_{2} \mathrm{CH}_{3}+\mathrm{H}_{2} \mathrm{CSCH}_{3} & \left(\mathrm{R}_{4}\right)
\end{array}
$$

3.4. SEM-EDAX Analysis. The SEM micrographs were taken to determine the morphology of the nanomaterials prepared. The existence of overlapping euhedral pseudo hexagonal platelets exhibiting dense-tight-thick layers was observed in the beneficiated kaolinite (Figures 3 and 4), a feature which is typical to most kaolinite minerals [53]. Following chemical treatment with salt solution this stacking sequence was observed to change to vermiform shaped particles mixed with skinny stacked euhedral pseudo hexagonal platelets (Figure 5). Salt treatment was therefore seen to possess the capacity to expose and activate the kaolinite functional layers 
TABLE 4: Band assignments for the ATR-FTIR absorption bands.

\begin{tabular}{|c|c|c|}
\hline Wavenumber $\left(\mathrm{cm}^{-1}\right)$ & Band assignment & Reference \\
\hline 3683,3684 , and 3693 & $\mathrm{OH}$ stretch for the Si-O-Si bonds on the lower octahedral surfaces of kaolinite & {$[23,24]$} \\
\hline $3618-3620$ & Inner hydroxyl groups between tetrahedral and octahedral kaolinite sheets & [24-26] \\
\hline 3650 & In-phase symmetrical stretch due to kaolinite sheets & {$[25,26]$} \\
\hline 3426 & $\mathrm{~N}-\mathrm{H}$ out-phase stretch due to urea & {$[27,28]$} \\
\hline 3340 & In-phase N-H stretch due to urea & {$[28,29]$} \\
\hline 3256 & $\begin{array}{l}\mathrm{OH} \text { stretching for } \mathrm{H} \text { bonding associated with urea-oligomer substitution within } \\
\text { kaolinite interlayer spaces }\end{array}$ & {$[30,31]$} \\
\hline 2970 & $\begin{array}{l}\mathrm{CH} \text { stretch/dimeric } \mathrm{OH} \text { stretch associated with DMSO decomposition during } \\
\text { calcination to form paraformaldehyde complexes }\end{array}$ & {$[32,33]$} \\
\hline 1738 & $\mathrm{C}=\mathrm{O}$ stretch due to intercalated urea & {$[32,33]$} \\
\hline 1669 & Free $\mathrm{C}=\mathrm{O}$ stretch and free $\mathrm{NH}_{2}$ bending & {$[34,35]$} \\
\hline 1587 & $\mathrm{C}-\mathrm{N}$ stretch due to urea & {$[34,35]$} \\
\hline 1461 & In-phase $\mathrm{CH}_{3}$ bending + scissoring $\mathrm{C}-\mathrm{N}$ vibrations & {$[34,35]$} \\
\hline 1438 & $\mathrm{~S}=\mathrm{O}$ sulfate ester stretching & {$[32,33]$} \\
\hline 1365 & $\mathrm{~S}=\mathrm{O}$ sulfonyl stretching & {$[32,33]$} \\
\hline $1202-1216$ & Amorphous $\mathrm{SiO}_{2}$ associated with calcination & {$[36,37]$} \\
\hline $1113-1149$ & Apical Si-O stretching & {$[23,24,26,38]$} \\
\hline 1047 & Si-O \& Si-O-Al stretching due to the presence of DMSO in the kaolinite & {$[37]$} \\
\hline $1023-1027$ & In-phase Si-O planar stretching & {$[23,24,26,39]$} \\
\hline $1001-997$ & Out-phase Si-O planar stretching and alternating Si-O \& Al-O bonds & {$[23,24,26,39,40]$} \\
\hline $910-900$ & $\mathrm{OH}$ deformation of inner hydroxyl group due to $\mathrm{Al}^{(\mathrm{VI})}-\mathrm{OH}$ bending vibrations & {$[23,24,39,41]$} \\
\hline $788-749$ & Al-O-Si asymmetric bending & {$[23,24,26,39,41]$} \\
\hline 777 and 434 & $\begin{array}{l}\mathrm{OH} \text { stretch associated with a change from octahedral } \mathrm{Al}^{3+} \text { in kaolinite to } \\
\text { tetrahedral coordination in metakaolinite }\end{array}$ & {$[23,24,26,39,41]$} \\
\hline 525 & Si-O- $\mathrm{Al}^{(\mathrm{VI})}$ bending vibration for the $\mathrm{Al}^{3+}$ in the octahedral configuration & {$[42]$} \\
\hline
\end{tabular}

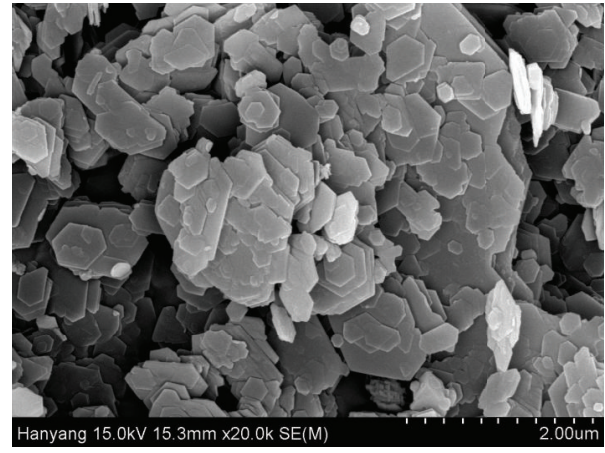

FIGURE 3: SEM micrograph of beneficiated kaolinite.

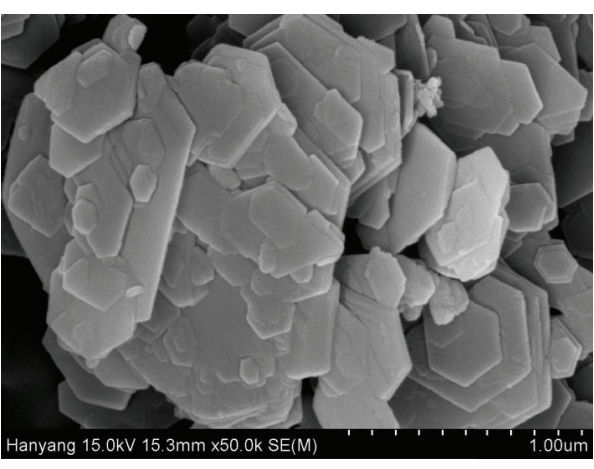

FIGURE 4: SEM micrograph of beneficiated kaolinite. thereby increasing the active surface area necessary for intercalation process.

The stacking sequence of the intermediate kaolinitehydroxyaluminum intercalation compound $\left(\mathrm{B}_{2}\right)$ when compared with the beneficiated kaolinite and the treated kaolinite $\left(B_{1}\right)$ revealed substantial changes in the morphology of kaolinite layers (Figures 3-5 and Figures 6(a) and 6(b)). As seen in $\mathrm{B}_{2}$ (Figures 6(a) and 6(b)), the kaolinite morphology was still vermicular, but the distance between layers has broadened as compared to beneficiated kaolinite and $\mathrm{B}_{1}$ which in turn explicates the expansion of interlayer distance following the intercalation of oligomeric cation.

Eventually, a complete disappearance of stacked layer sequences when urea replaced hydroxyaluminum oligomers in the kaolinite interlayer spaces was observed (Figures 7(a) and $7(b)$ ). This observation was attributed to the formation of a well-packed urea-kaolinite intercalation compound.

Furthermore, during the first attempt of coupling: DMSO-kaolinite intercalation $\rightarrow$ calcination $\rightarrow$ hydroxyaluminum-kaolinite reintercalation and then urea substitution 


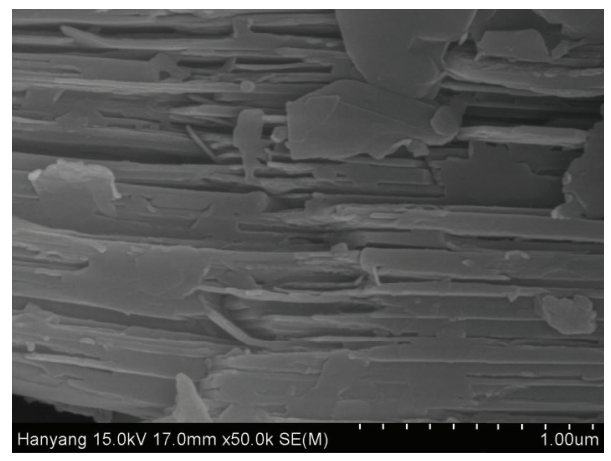

Figure 5: SEM micrograph of $B_{1}$.

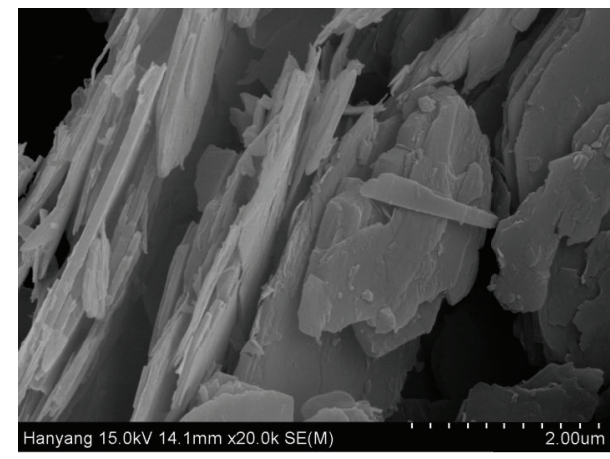

(a)

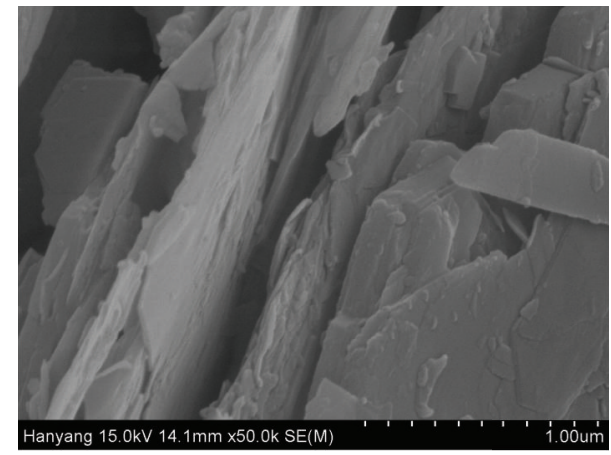

(b)

FIGURE 6: SEM micrograph of $\mathrm{B}_{2}$.

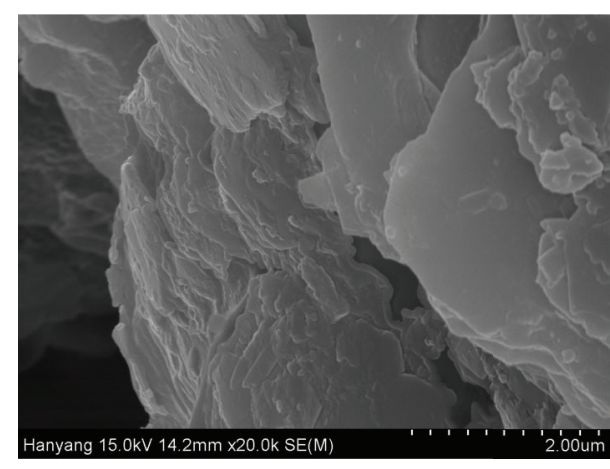

(a)

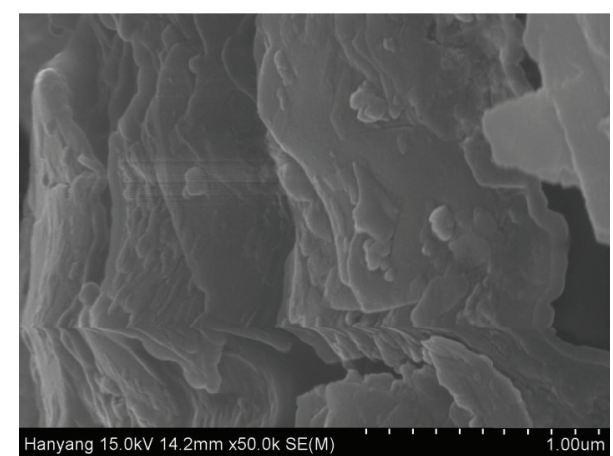

(b)

FIGURE 7: SEM micrograph of $\mathrm{B}_{3}$.

in the hydroxyaluminum reintercalated kaolinite, there was a transitional transformation from the vermicular morphology observed before into nanostructures resembling like a "pimpled surfaces" or rather like a "pustulated skin" wherein the particles were self-assembled into a woven network pattern (Figures 8(a) and 8(b)). A complete transformation was observed after aging and maturation of $\mathrm{B}_{5}$ (observed in Figure 8) to $B_{5}$ (observed in Figure 9) which exhibited a unique curling behavior resembling like a perforated glomeruli embedded on each other to form a pattern like desert cactus. These phenomena were associated with the tendency of hydroxyaluminum oligomer to curl during air drying thereby creating an alternating aluminum chlorohydrate water arrangement and then diffusion of water between the aluminum chlorohydrate layers during air drying resulting in a curled film [54].

The self-assembled nanostructures observed in $B_{5}$ were analyzed for elemental composition with EDX (Figure 10) and results indicated the presence of nitrogen from urea so revealing the fact the nanocomposites $\left(\mathrm{B}_{5}\right)$ can be used in the formulation of controlled release systems such as (urea) controlled release fertilizers and the drug delivery systems. 


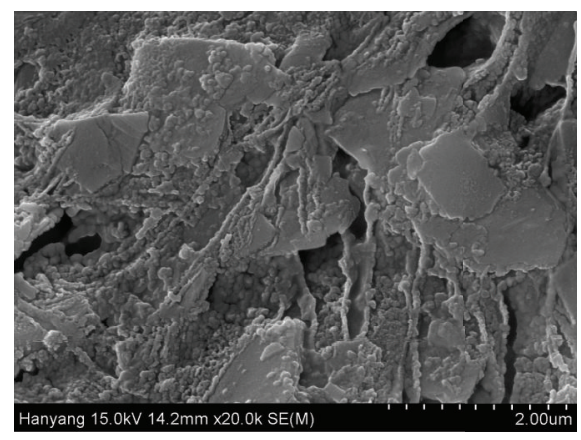

(a)

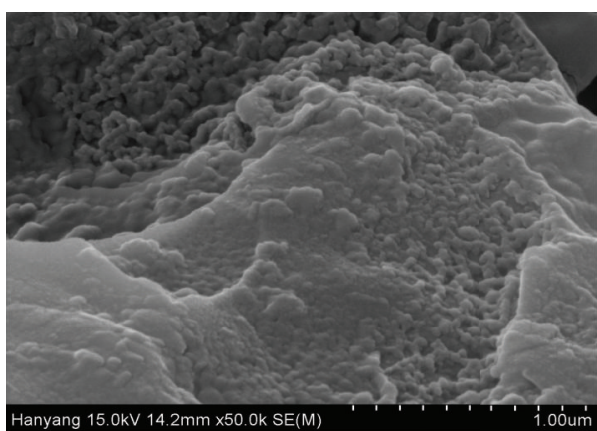

(b)

FIGURE 8: SEM micrograph of transitional $\mathrm{B}_{5}$.

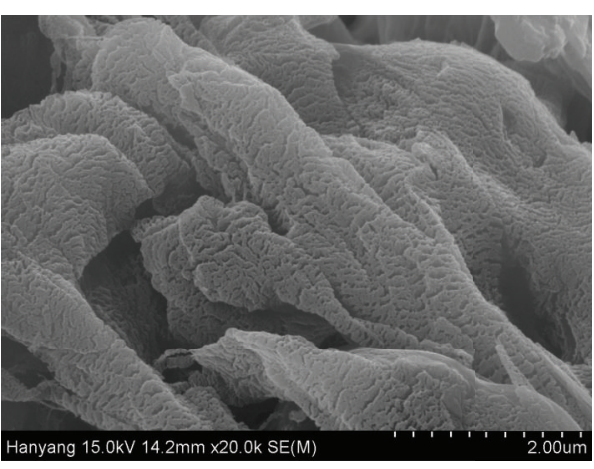

(a)

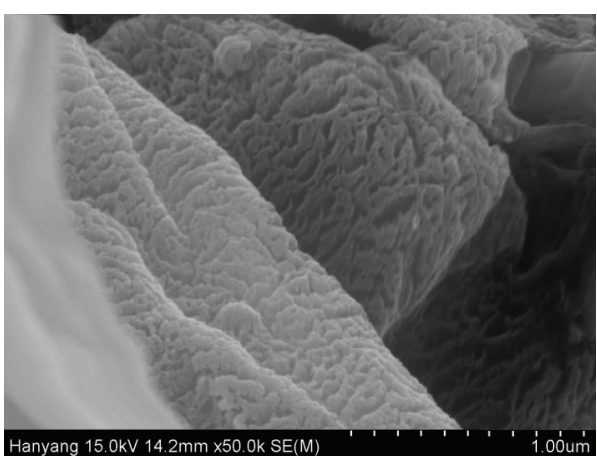

(b)

FIGURE 9: SEM micrograph of $B_{5}$.

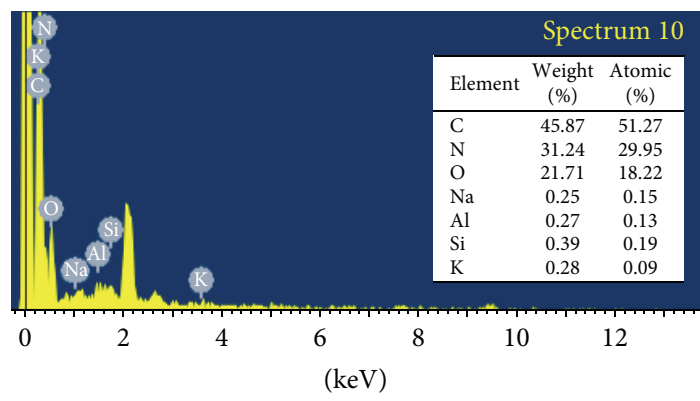

Full scale 241 cts cursor: 0.000

Figure 10: Composition of $\mathrm{B}_{5}$ from EDAX.

3.5. TG-DTG Analysis. Thermogravimetric analysis was done under $\mathrm{N}_{2}$ atmosphere to investigate the thermal degradation and stability of aluminum oligomer intercalated kaolinite compounds to a maximum of about $800^{\circ} \mathrm{C}$.

As can be seen in Figure 11, $\mathrm{B}_{2}$ was characterized by 4 degradation phases which include $25-250^{\circ} \mathrm{C}, 250-450^{\circ} \mathrm{C}$, $500-650^{\circ} \mathrm{C}$, and $670-800^{\circ} \mathrm{C}$, respectively, corresponding to the removal of moisture that is externally adsorbed on the surfaces as well the decomposition of Kegging ions or Kegging cluster (resulting from polymerization of hydroxyaluminum oligomers into large discrete anions in the form of

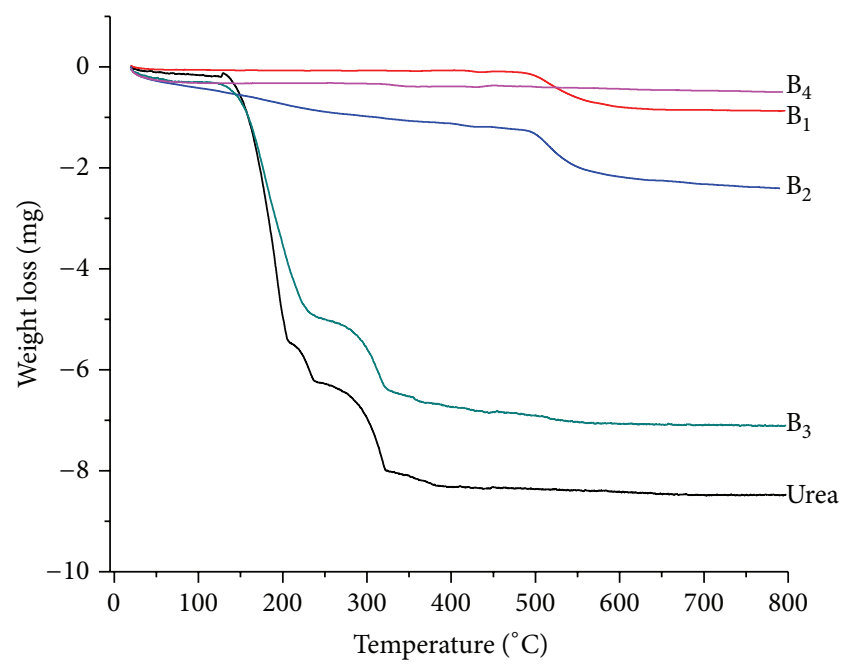

FIgURE 11: TGA thermograms for Urea, $B_{1}, B_{2}, B_{3}$, and $B_{4}$.

$\left[\mathrm{H}_{2} \mathrm{~W}_{12} \mathrm{O}_{40}\right]^{6-}$ which undergo condensation in the interlayer spaces thereby forming higher polymers such as the $\mathrm{Al}_{24}$ polycations) associated with the calcination of $\mathrm{B}_{2}$ [55-57]; also, it corresponds to the removal of water molecules bonded to the aluminum atoms on the Keggin cluster [58]. This observation agrees with the fact that "water molecules bonded to 
the aluminum atoms on the Keggin cluster are more likely to be removed around $150-300^{\circ} \mathrm{C}^{\prime \prime}[58,59]$. The decomposition along $250-450^{\circ} \mathrm{C}$ and $500-650^{\circ} \mathrm{C}$ corresponds to the liberation of interlayer water, kaolinite hydroxylation reactions, and $\mathrm{CO}_{2}$ associated with the decomposition of $\mathrm{B}_{2}$ [58] whereas the phase around $670-800^{\circ} \mathrm{C}$ corresponds to both kaolinite dehydroxylation and the kaolinite dehydroxylation transformation phases [60-62].

When urea replaced hydroxyaluminum oligomer, the externally adsorbed water and the elimination of structural water were observed in the first and second degradation phases that is $25-70$ and $75-230^{\circ} \mathrm{C}$, respectively. The second and third degradation phases around $75-230^{\circ} \mathrm{C}$ and 250 $320^{\circ} \mathrm{C}$ correspond to both urea vaporization and its complementary degradation compound biuret $\left[\mathrm{NH}(\mathrm{CO})_{2}(\mathrm{NH} 2)_{2}\right]$, respectively. Preliminary kaolinite dehydroxylation as well as continuous sublimation of urea to its complex decomposition product corresponds to fourth and fifth degradation phases seen at $350-550^{\circ} \mathrm{C}$ and $550-800^{\circ} \mathrm{C}[63]$, respectively.

\section{Conclusion}

The effect of coupling DMSO and oligomeric hydroxyaluminum intercalating species via calcination as an intermediate step on the properties of kaolinite morphology was investigated. The raw kaolinite was wet beneficiated and then modified with sodium chloride solution. Matured and aged hydroxyaluminum cationic oligomers were prepared and used as intermediate intercalation compounds for the intercalation of urea into the kaolinite interlayer spaces. The effect of reintercalating urea into the calcined DMSO intercalated kaolinite via hydroxyaluminum oligomeric cations as intermediate step was also investigated; the resulting nanomaterials were characterized with XRF, ATR-FTIR, XRD DT/DTG, SEM, and EDX. The percentage intercalation ratios attained were $89.2,51.2,32.4,7.0$, and 38.4 for the DMSO intercalated kaolinite, hydroxyaluminum intercalated kaolinite, urea intercalated kaolinite, calcined DMSO intercalated kaolinite, and the urea-kaolinite reintercalated nanocomposites; their particle sizes were in average $60.01 \mathrm{~nm}, 32.62 \mathrm{~nm}, 40.81 \mathrm{~nm}$, $21.72 \mathrm{~nm}$, and $40.75 \mathrm{~nm}$, respectively. Despite the variations in the kaolinite treatments, the average lattice parameter was in average $12.59 \AA$ and the Bravais crystal lattice was FCC structure. Unique curling patterns were observed when kaolinite was treated with the intermediate intercalating species and calcined and then reintercalated with urea. These include a change from the normal stacked frequency of euhedral pseudo hexagonal platelets of the kaolinite to vermiform morphologies and then to pustulated form and finally into a unique curled pattern which exhibited what we have called a curled glomeruli-like shape organized into self-assembled structure resembling a desert cactus.

\section{Conflict of Interests}

The authors declare that there is no conflict of interests regarding the publication of this paper.

\section{Acknowledgments}

The authors are grateful to the Nelson Mandela African Institution of Science and Technology as well as the Department of Chemical Engineering, Hanyang University, for financial support and the SEAMIC center for technical assistance. Appreciations for typesetting and moral support are ascribed to Miss Niconia Amos Bura from the Ministry of Education and Vocational Training Tanzania.

\section{References}

[1] P. B. Lajos, "World reference base for soil resources," in Soil Science: Sources of Negative Charge, TÁMOP 4.1.2 Pályázat Keretein Belül, Debreceni Egyetem, Debrecen, Hungary, 2008.

[2] S. I. Sempeho, H. T. Kim, E. Mubofu, and A. Hilonga, "Meticulous overview on the controlled release fertilizers," Advances in Chemistry, vol. 2014, Article ID 363071, 16 pages, 2014.

[3] F. C. H. Pinto, A. Silva-Cunha, G. A. Pianetti, E. Ayres, R. L. Oréfice, and G. R. Da Silva, "Montmorillonite clay-based polyurethane nanocomposite as local triamcinolone acetonide delivery system," Journal of Nanomaterials, vol. 2011, Article ID 528628, 11 pages, 2011.

[4] B. K. Nandi, A. Goswami, and M. K. Purkait, "Removal of cationic dyes from aqueous solutions by kaolin: kinetic and equilibrium studies," Applied Clay Science, vol. 42, no. 3-4, pp. 583-590, 2009.

[5] B. Li, J. He, D. G. Evans, and X. Duan, "Inorganic layered double hydroxides as a drug delivery system-intercalation and in vitro release of fenbufen," Applied Clay Science, vol. 27, no. 3-4, pp. 199-207, 2004.

[6] U. Kielmann, G. Jeschke, and I. García-Rubio, "Structural characterization of polymer-clay nanocomposites prepared by co-precipitation using EPR techniques," Materials, vol. 7, no. 2, pp. 1384-1408, 2014.

[7] P. Khazaeli, A. Pardakhty, and F. Hassanzadeh, "Formulation of ibuprofen beads by ionotropic gelation," Iranian Journal of Pharmaceutical Research, vol. 7, no. 3, pp. 163-170, 2008.

[8] B. D. Kevadiya, T. A. Patel, D. D. Jhala et al., "Layered inorganic nanocomposites: a promising carrier for 5-fluorouracil (5-FU)," European Journal of Pharmaceutics and Biopharmaceutics, vol. 81, no. 1, pp. 91-101, 2012.

[9] B. D. Kevadiya, H. A. Patel, G. V. Joshi, S. H. R. Abdi, and H. C. Bajaj, "Montmorillonite-alginate composites as a drug delivery system: intercalation and in vitro release of diclofenac sodium," Indian Journal of Pharmaceutical Sciences, vol. 72, no. 6, pp. 732737, 2010

[10] G. V. Joshi, B. D. Kevadiya, H. A. Patel, H. C. Bajaj, and R. V. Jasra, "Montmorillonite as a drug delivery system: intercalation and in vitro release of timolol maleate," International Journal of Pharmaceutics, vol. 374, no. 1-2, pp. 53-57, 2009.

[11] S. Sunardi, U. Irawati, Y. Arryanto, and Sutarno, "Modified kaolin with cationic surfactant for gibberellic acid carrier materials," Indonesian Journal of Chemistry, vol. 11, no. 1, pp. 96102, 2011.

[12] D. M. MacEwan, "The nomenclature of the halloysite minerals," Mineralogical Magazine, vol. 28, no. 196, pp. 36-44, 1947.

[13] R. Suresh, S. N. Borkar, V. S. Shende, and S. K. Dimble, "Nanoclay drug delivery system," International Journal of Pharmaceutical Sciences and Nanotechnology, vol. 3, pp. 901-905, 2010. 
[14] E. P. Giannelis, "Polymer layered silicate nanocomposites," Advanced Materials, vol. 8, no. 1, pp. 29-35, 1996.

[15] H. Li, G. Sheng, B. J. Teppen, C. T. Johnston, and S. A. Boyd, "Sorption and desorption of pesticides by clay minerals and humic acid-clay complexes," Soil Science Society of America Journal, vol. 67, no. 1, pp. 122-131, 2003.

[16] B. T. Bowman, "The effect of saturating cations on the adsorption of Dasanit, O, O-diethyl O-[p-(methyl sulfinyl) phenyl] phosphorothioate, by montmorillonite suspensions," Soil Science Society of America Journal, vol. 37, no. 2, pp. 200-207, 1973.

[17] M. M. Loux, R. A. Liebl, and F. W. Slife, "Adsorption of clomazone on soils, sediments, and clays," Weed Science, vol. 37, no. 3 , pp. 440-444, 1989.

[18] B. L. Sawhney and S. S. Singh, "Sorption of atrazine by Al- and Ca-saturated smectite," Clays and Clay Minerals, vol. 45, no. 3, pp. 333-338, 1997.

[19] C. T. Johnston, M. F. De Oliveira, B. J. Teppen, G. Sheng, and S. A. Boyd, "Spectroscopic study of nitroaromatic-smectite sorption mechanisms," Environmental Science \& Technology, vol. 35, no. 24, pp. 4767-4772, 2001.

[20] W. F. Jaynes and S. A. Boyd, "Hydrophobicity of siloxane surfaces in smectites as revealed by aromatic hydrocarbon adsorption from water," Clays and Clay Minerals, vol. 39, no. 4, pp. 428-436, 1991.

[21] D. A. Laird and P. D. Fleming, "Mechanisms for adsorption of organic bases on hydrated smectite surfaces," Environmental Toxicology and Chemistry, vol. 18, no. 8, pp. 1668-1672, 1999.

[22] E. H. J. Lugwisha and S. I. Siafu, "The properties of feldspathic dental porcelain from tanzanian aluminosilicate materials," International Journal of Development Research, vol. 4, no. 11, pp. 2660-2265, 2014.

[23] M. M. Dawley, A. M. Scott, F. C. Hill, J. Leszczynski, and T. M. Orlando, "Adsorption of formamide on kaolinite surfaces: a combined infrared experimental and theoretical study," The Journal of Physical Chemistry C, vol. 116, no. 45, pp. 23981-23991, 2012.

[24] C. O. Mgbemena, N. O. Ibekwe, R. Sukumar, and A. R. R. Menon, "Characterization of kaolin intercalates of oleochemicals derived from rubber seed (Hevea brasiliensis) and tea seed (Camelia sinensis) oils," Journal of King Saud UniversityScience, vol. 25, no. 2, pp. 149-155, 2013.

[25] J. Madejová, "FTIR techniques in clay mineral studies," Vibrational Spectroscopy, vol. 31, no. 1, pp. 1-10, 2003.

[26] U. Aroke and U. El-Nafaty, "XRF, XRD and FTIR properties and characterization of HDTMA-Br surface modified organokaolinite clay," International Journal of Emerging Technology and Advanced Engineering, vol. 4, no. 4, 2014.

[27] P. Larkin, Infrared and Raman Spectroscopy; Principles and Spectral Interpretation, Elsevier, 2011.

[28] P. H. Fischer and C. A. McDowell, "The infrared absorption spectra of urea-hydrocarbon adducts," Canadian Journal of Chemistry, vol. 38, no. 2, pp. 187-193, 1960.

[29] E. Horváth, J. Kristóf, and R. L. Frost, "Vibrational spectroscopy of intercalated kaolinites. Part I," Applied Spectroscopy Reviews, vol. 45, no. 2, pp. 130-147, 2010.

[30] V. T. Padil, N. H. Nguyen, A. Ševců, and M. Černík, "Fabrication, characterization, and antibacterial properties of electrospun membrane composed of Gum karaya, polyvinyl alcohol, and silver nanoparticles," Journal of Nanomaterials, vol. 2015, Article ID 750726, 10 pages, 2015.
[31] N. A. Almuslet, E. A. Hassan, A. S. A.-E. Al-Sherbini, and M. G. A. Muhgoub, "Diode laser $(532 \mathrm{~nm})$ induced grafting of polyacrylamide onto Gum Arabic," Journal of Physical Science, vol. 23, no. 2, pp. 43-53, 2012.

[32] G. C. Corporation, Technical Bulletin Reaction Solvent Dimethyl Sulfoxide (DMSO), 2005, http://www.gaylordchemical.com/.

[33] C. C. Gaylord, Dimethyl Sulfoxide (DMSO) Physical Properties, Gaylord Chemical Corporation, Slidell, La, USA, 2005.

[34] H. Becher, "Infrared spectroscopic examination of the reaction products of urea and formaldehyde. I. Methylene ureas," Chemische Berichte, vol. 89, pp. 1593-1601, 1956.

[35] Z. Piasek and T. Urbanski, "The infrared absorption spectrum and structure of urea," Bulletin de l'Académie Polonaise des Sciences: Série des Sciences Chimiques, vol. 10, pp. 113-120, 1962.

[36] B. R. Ilić, A. A. Mitrović, and L. R. Miličić, “Thermal treatment of kaolin clay to obtain metakaolin," Hemijska Industrija, vol. 64, no. 4, pp. 351-356, 2010.

[37] M. A. Soleimani, R. Naghizadeh, A. R. Mirhabibi, and F. Golestanifard, "Effect of calcination temperature of the kaolin and molar $\mathrm{Na}_{2} \mathrm{O} / \mathrm{SiO}_{2}$ activator ratio on physical and microstructural properties of metakaolin based geopolymers," Iranian Journal of Materials Science \& Engineering, vol. 9, no. 4, 2012.

[38] E. Balan, A. M. Saitta, F. Mauri, and G. Calas, "First-principles modeling of the infrared spectrum of kaolinite," The American Mineralogist, vol. 86, no. 11-12, pp. 1321-1330, 2001.

[39] C. Y. Heah, H. Kamarudin, A. M. Mustafa Al Bakri et al., "Study on solids-to-liquid and alkaline activator ratios on kaolin-based geopolymers," Construction and Building Materials, vol. 35, pp. 912-922, 2012.

[40] T. H. Dang, B.-H. Chen, and D.-J. Lee, "Application of kaolinbased catalysts in biodiesel production via transesterification of vegetable oils in excess methanol," Bioresource Technology, vol. 145, pp. 175-181, 2013.

[41] Y. M. Liew, H. Kamarudin, A. M. Mustafa Al Bakri et al., "Processing and characterization of calcined kaolin cement powder," Construction and Building Materials, vol. 30, pp. 794802, 2012.

[42] A. Tironi, M. Trezza, E. Irassar, and A. Scian, "Thermal treatment of kaolin: effect on the pozzolanic activity," Procedia Materials Science, vol. 1, pp. 343-350, 2012.

[43] Ciros, "Ball clay beneficiation technology," 2013, http://www .nmcorp.co.in/ore-beneficiation/4242-ball-clay-beneficiationtechnology.html, http://pillowshotelcebu.com/focusmining/ 2174-ball-clay-chemical-composition.html.

[44] M. Jovanović and V.-H. Tatjana, "Influence of sintering temperature on raw and beneficiated clay 'Klokoti,' Science of Sintering, vol. 44, no. 2, pp. 161-168, 2012.

[45] M. Jovanović and A. Mujkanović, Characterization, Beneficiation and Utilization of the Clay from Cental Bosnia, B\&H, 2013.

[46] H. Stein and N. Cheremisinoff, Encyclopedia of Fluid Mechanics: Slurry Flow Technology, vol. 5, Gulf Publishing, Houston, Tex, USA, 1986.

[47] R. T. Martin, "Process for mineral beneficiation," Google Patents, 1984.

[48] R. R. Oder, "High gradient magnetic separation theory and applications," IEEE Transactions on Magnetics, vol. 12, no. 5, pp. 428-435, 1976.

[49] H. A. Patel, R. S. Somani, H. C. Bajaj, and R. V. Jasra, "Synthesis and characterization of organic bentonite using Gujarat and Rajasthan clays," Current Science, vol. 92, no. 7, p. 1004, 2007. 
[50] G. Brown and G. Brindley, "X-ray diffraction procedures for clay mineral identification," in Crystal Structures of Clay Minerals and Their X-Ray Identification, vol. 5, pp. 305-359, GeoScienceWorld, 1980.

[51] S. I. Sempeho and E. H. J. Lugwisha, "The properties of feldspathic dental porcelain from Tanzanian aluminosilicate materials," International Journal of Development Research, vol. 4, no. 11, pp. 2260-2265, 2014.

[52] E. H. J. Lugwisha and S. I. Siafu, "The properties of feldspathic dental porcelain from Tanzanian aluminosilicate materials," International Journal of Development Research, vol. 4, no. 11, pp. 2260-2265, 2014.

[53] P. J. R. Uwins, I. D. R. Mackinnon, J. G. Thompson, and A. J. E. Yago, "Kaolinite-NMF intercalates," Clays and Clay Minerals, vol. 41, no. 6, pp. 707-717, 1993.

[54] D. L. Teagarden, S. L. Hem, and J. L. White, "Conversion of aluminum chlorohydrate to aluminum hydroxide," Journal of the Society of Cosmetic Chemists, vol. 33, pp. 281-295, 1982.

[55] I. J. McColm and L. S. O'Bannon, Dictionary of Ceramic Science and Engineering, Springer, 1994.

[56] G. Fu, L. Nazar, and A. Bain, "Aging processes of alumina sol-gels: characterization of new aluminum polyoxycations by aluminum-27 NMR spectroscopy," Chemistry of Materials, vol. 3, no. 4, pp. 602-610, 1991.

[57] S. M. Thomas and M. L. Occelli, "Effects of synthesis conditions on the thermal stability of a Texas montmorillonite expanded with $\left[\mathrm{Al}_{13} \mathrm{O}_{4}(\mathrm{OH})_{24}\left(\mathrm{H}_{2} \mathrm{O}\right)_{12}\right]^{7+}$ cations," Clays and Clay Minerals, vol. 48, no. 2, pp. 304-308, 2000.

[58] S. Abeysinghe, "Keggin-type aluminum nanoclusters: synthesis, structural characterization and environmental implications," in Chemistry, University of Iowa, Iowa City, Iowa, USA, 2012.

[59] M. L. Occelli and R. M. Tindwa, "Physicochemical properties of montmorillonite interlayered with cationic oxyaluminum pillars," Clays \& Clay Minerals, vol. 31, no. 1, pp. 22-28, 1983.

[60] F. Vaughan, "Energy changes when kaolin minerals are heated," Clay Minerals, vol. 2, no. 13, pp. 265-274, 1955.

[61] E. I. Pereira, F. B. Minussi, C. C. T. da Cruz, A. C. C. Bernardi, and C. Ribeiro, "Urea-montmorillonite-extruded nanocomposites: a novel slow-release material," Journal of Agricultural and Food Chemistry, vol. 60, no. 21, pp. 5267-5272, 2012.

[62] A. Czarnecka, Preparation and characterization of kaolinitebased nanocomposite materials [Ph.D. thesis], University of Ottawa, Ottawa, Canada, 2013.

[63] M. M. E. Costa, E. C. M. Cabral-Albuquerque, T. L. M. Alves, J. C. Pinto, and R. L. Fialho, "Use of polyhydroxybutyrate and ethyl cellulose for coating of urea granules," Journal of Agricultural and Food Chemistry, vol. 61, no. 42, pp. 9984-9991, 2013. 

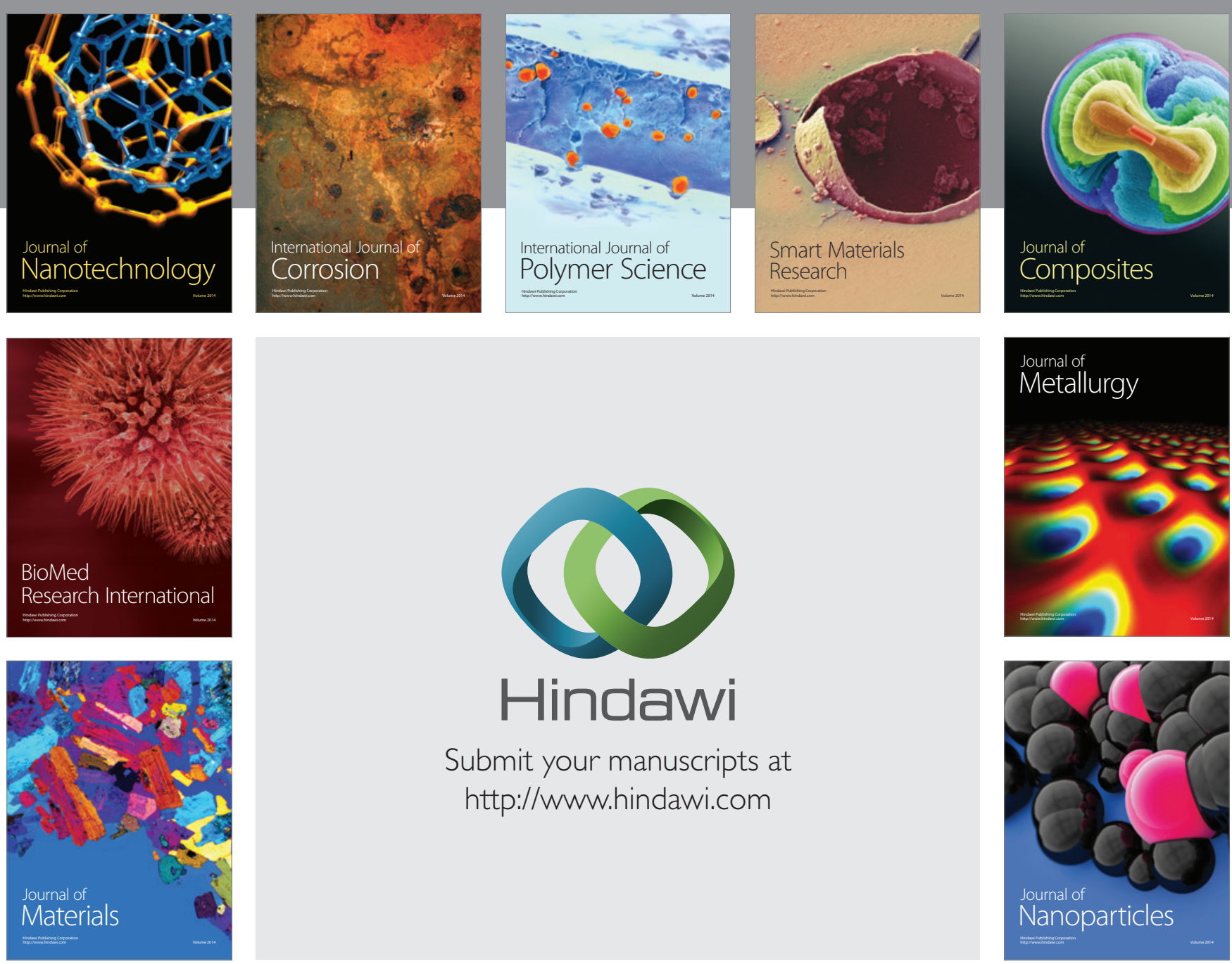

Submit your manuscripts at http://www.hindawi.com
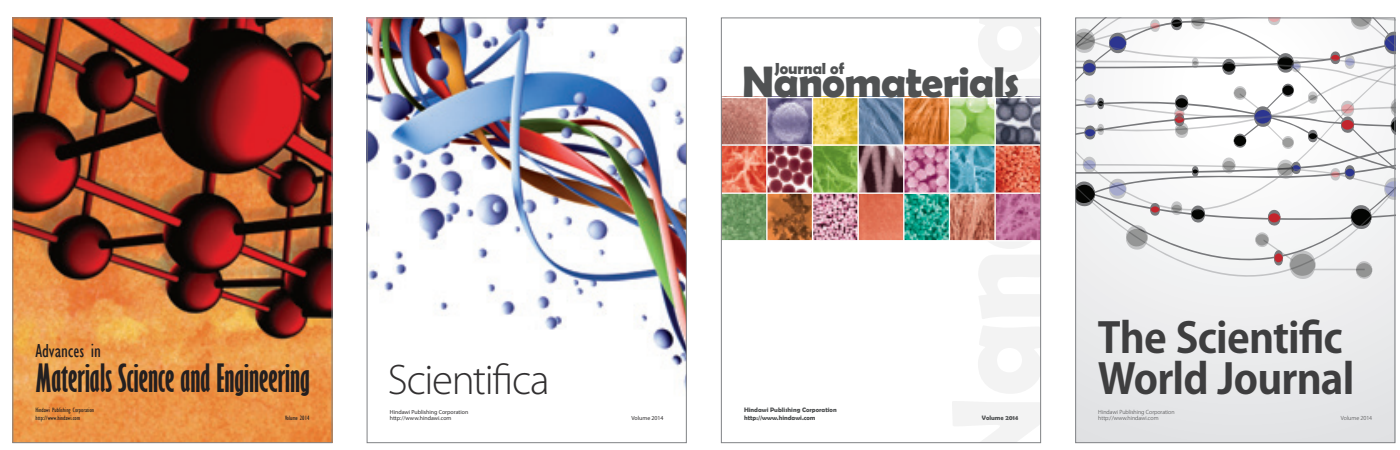

\section{The Scientific World Journal}
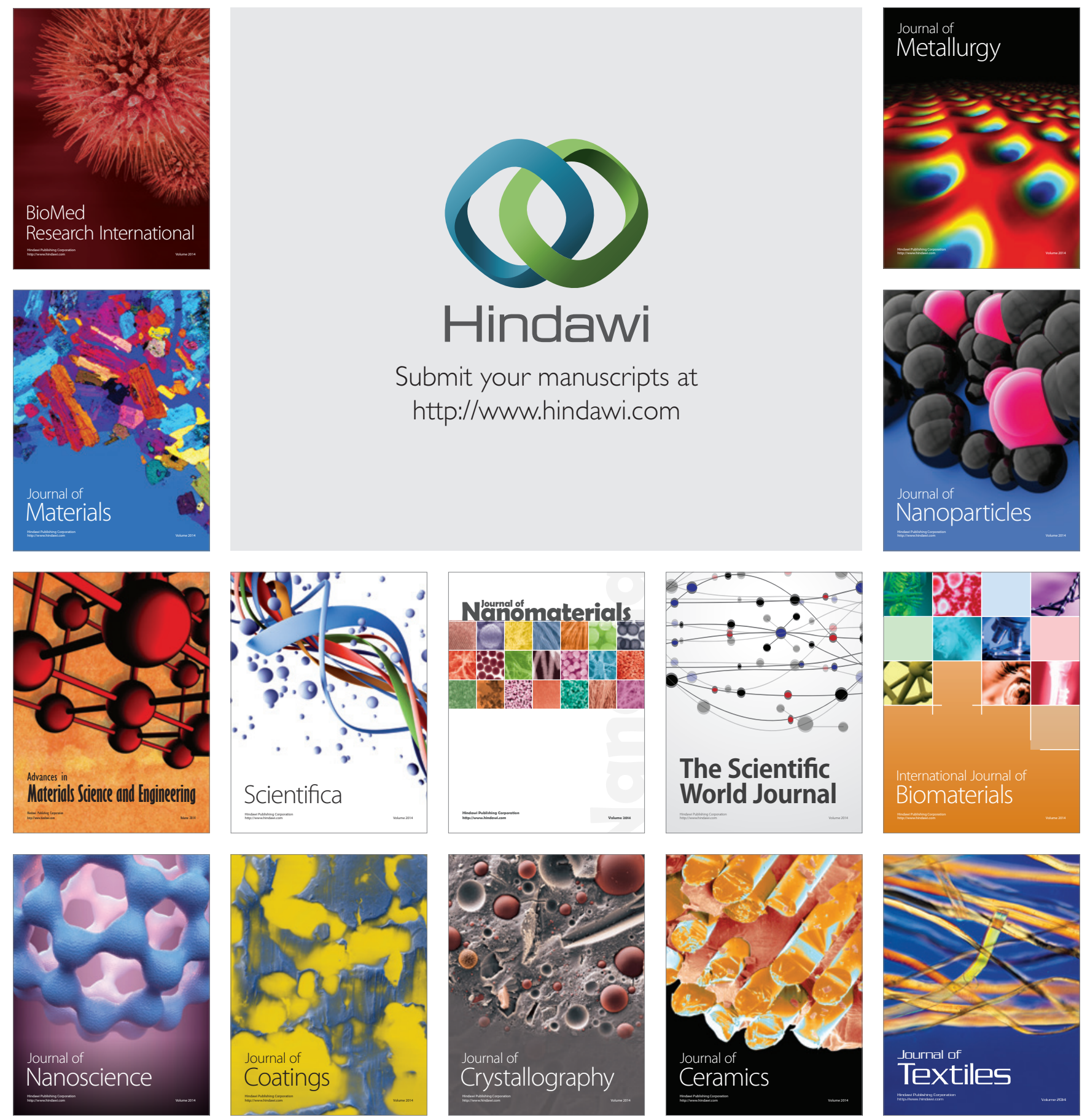